\title{
NEUROPEPTIDES
}

Neuropeptides (1987) 9, 269-282

(C) Longman Group UK Ltd 1987

\section{GAMMA MELANOTROPIN RESPONSE TO OVINE CORTICOTROPIN RELEASING FACTOR IN NORMAL HUMANS}

James H. Meador-Woodruff, Stanley J. Watson, Virginia Murphy-Weinberg, Sylvie Jegoul, Hubert Vaudry ${ }^{1}$, Nabil G. Seidah ${ }^{2}$, Jean Rivier ${ }^{3}$ Wylie Vale ${ }^{3}$, Huda Akil

Mental Health Research Institute and Department of Psychiatry, University of Michigan, Ann Arbor, Michigan 48109-0720; Laboratoire d'Endocrinologie, Faculte des Sciences et Techniques, France; ${ }^{2}$ Institut De Recherches Cliniques De Montreal, Clinical Research Institute of Montreal, Montreal, Canada; ${ }^{3}$ Clayton Foundation Laboratories for Peptide Biology, The Salk Institute, La Jolla, CA 92037. (Reprint Requests to JHM-W)

\section{ABSTRACT}

Plasma $\gamma$-melanotropin was measured by a $\gamma_{3}$ MSH-specific radioimmunoassay before and after a single bolus intravenous infusion of ovine corticotropin releasing factor (oCRF; $0.1 \mathrm{ug} / \mathrm{kg}$ ) in seven normal men. A significant increase of $\gamma_{3} \mathrm{MSH}$ was observed 15 minutes post-oCRF infusion, which paralleled a similar increase in plasma cortisol. Gel filtration chromatography revealed that the observed increase was attributable to elevations of $9 \mathrm{~K}$ and $4 \mathrm{~K}$ forms of $\gamma_{3} \mathrm{MSH}$ immunoreactivity. Affinity chromatography demonstrated that the majority of $\gamma_{3}$ MSH immunoreactivity in human plasma is glycosylated. As the smaller forms of $\gamma_{3} \mathrm{MSH}$ are felt to have endocrine activity at the adrenal cortex, these changes may be physiologically relevant.

\section{INTRODUCTION}

$\gamma$-melanotropin $\left(\gamma_{3} \mathrm{MSH}\right)$ is a 27 -residue peptide found within the $\mathrm{N}$-terminal domain of proopiomelanocortin (POMC) containing the sequence His-Phe-Arg-Trp in common with $\alpha$ - and $\beta$-MSH (21). There are two major dibasic cleavage sites in the $16 \mathrm{~K} \mathrm{~N}$-terminal region of POMC, potentially generating the extreme $N$-terminal peptide, $\gamma_{3} M S H$, and joining peptide, that segment between $\gamma_{3} \mathrm{MSH}$ and adrenocorticotropin $(\mathrm{ACTH})$. In theory, $\gamma_{3} \mathrm{MSH}$ could thus be associated with joining peptide (POMC ${ }^{65-103}$, estimated molecular weight 8-10K, depending on the extent of glycosylation), the extreme N-terminal fragment of POMC (POMC ${ }^{1-77}$, estimated molecular weight 9-11K), or alone (POMC $51-77$, molecular weight $3-4 \mathrm{~K}$ ). In humans, an additional cleavage site is located within $\gamma_{3} \mathrm{MSH}$, potentially yielding a 12-residue peptide ( $\gamma_{2} \mathrm{MSH}$ ), or an 11-residue, C-amidated peptide, $\gamma_{1}$ MSH (18). These theoretical products, however, have not been demonstrated in human anterior pituitary $(33,35)$, and a larger peptide is assumed to be the circulating form in plasma $(32,33)$. 
The extent of processing of $\gamma$-melanotropin in the plasma of physiologically normal humans has not been elucidated. Metapyrone has been shown to facilitate an elevation of $\gamma$-melanotropin in normal humans (15) which is attributable to an elevation of $16 \mathrm{~K}$-sized material (33), presumably the intact $\mathrm{N}$-terminal domain of POMC. The existence of more processed, smaller forms of circulating $\gamma$-melanotropin, however, may be physiologically relevant. $\gamma_{3} \mathrm{MSH}$, for example, is able to bind to the adrenal cortex (25), and can potentiate ACTH-induced adrenal steroidogenesis $(1,2,13,24)$. Additionally, $\gamma$, MSH has been demonstrated to have potent cardiovascular $(8,9,17)$ and renal (19) effects, as well as the ability to induce behavioral changes in rats (23). No potential physiological effects, however, have been demonstrated of any of the possible larger forms of $\gamma$-melanotropin.

The release of $\gamma$-MSH from the anterior pituitary into plasma is probably mediated by corticotropin releasing factor ( CRF). Using an antibody specific for the N-terminal domain of POMC (POMC ${ }^{1-76}$ ), Chan et al. (10) demonstrated that this larger form of $\gamma$-melanotropin, ACTH, and $B$-endorphin were released in equimolar amounts following ovine CRF (OCRF) stimulation of cultured human anterior pituitary cells. Several reports $(14,20)$ have since indicated that total plasma $\gamma_{3} \mathrm{MSH}$ immunoreactivity (IR) increases in normal humans following oCRF infusion, but the specific forms released (i.e., $\gamma_{3} \mathrm{MSH}$, the entire $16 \mathrm{~K}$ $\mathrm{N}$-terminal domain of POMC, or intermediate-sized products) were not determined. As CRF is likely a physiological mediator of $\gamma_{3} \mathrm{MSH}$ release, and the extent of processing of circulating $\gamma_{3}$ MSH-IR may reflect relevant endocrine activity, we undertook the present investigation to explore the effect of oCRF infusion on the pituitary release into plasia of the various possible forms of $\gamma_{3}$ MSH-IR in normal human males.

\section{METHODS}

Subjects. Seven male volunteers (age 20-30) were studied. Each subject had an unremarkable medical history as well as normal physical and psychiatric examinations. Each had normal laboratory tests including an electrocardiogram, serum electrolytes and glucose, liver, renal, and thyroid function tests, complete blood count and a urine drug screen. Written informed consent was obtained from each subject for participation in this study.

Preparation of CRF. Synthetic ovine CRF (synthesized and characterized by J.R. and W.V.) was prepared for injection by the University of Michigan Medical Center Pharmacy. Ten to $12 \mathrm{mg}$ of material was dissolved in $10 \mathrm{ml}$ of a vehicle solution of $5 \%$ human albumin, $0.9 \%$ benzyl alcohol, $0.001 \mathrm{~N} \mathrm{HCl,} 0.1 \%$ lactose and $0.01 \%$ ascorbic acid, and was sterilized by filtration. This material was then diluted ten-fold in $0.9 \% \mathrm{NaCl}$ containing $0.001 \mathrm{~N} \mathrm{HCl}$. This stock material was diluted another ten-fold with the original vehicle above, yielding a theoretical concentration of $10 \mathrm{ug} / \mathrm{ml}$. This solution was stored in $\mathrm{l} \mathrm{ml}$ aliquots in sterile amber glass bottles at $-20^{\circ} \mathrm{C}$ until use. Random vials were assayed for both oCRF immunoreactivity and biological activity in rat anterior pituitary cell cultures (36). For injection, vials were thawed 10 minutes prior to infusion; all transfer syringes and needles were coated with vehicle solution, and the $O C R F$ was diluted in this vehicle to a final concentration equivalent to $0.1 \mathrm{ug} / \mathrm{kg}$ body weight for each subject (total volume injected $0.2-0.5 \mathrm{~m} 1$ ). 
Infusion paradigm. Subjects presented to the Clinical Research Center of the University of Michigan at $12: 30 \mathrm{p.m.}$, after having their usual lunch. Intravenous catheters were inserted in the median antecubital veins of both arms. One catheter was fitted with a heparin lock for withdrawal of blood samples; the other catheter was maintained open with a slow drip of isotonic intravenous fluid for injection purposes. At $1: 30 \mathrm{p} . \mathrm{m}$., a control injection of $0.9 \%$ saline was given; at $2: 00 \mathrm{p} . \mathrm{m}$., a vehicle-control injection was given. At $2: 20$ p.m., $175-200 \mathrm{~m} 1$ of blood was withdrawn for plasma $\gamma_{3} \mathrm{MSH}$ determination. At $2: 30 \mathrm{p} \cdot \mathrm{m} ., 0.1 \mathrm{ug} / \mathrm{kg}$ OCRF was injected (over 10-15 seconds), followed by a $1 \mathrm{ml}$ flush with vehicle. We have previously found that the maximum response to OCRF of plasma $B$-endorphin and $\gamma_{3}$ MSH levels occurs between 10 and 15 minutes post-oCRF infusion (unpublished observation). Accordingly, at $2: 45 \mathrm{p} . \mathrm{m}$. a second $175-200 \mathrm{ml}$ blood sample was obtained for $\gamma_{3} \mathrm{MSH}$ quantitation. In addition, plasma was obtained for cortisol determination 5 minutes before and 15 minutes after the saline and vehicle injections as well as 5 minutes before and at $5,10,15,30,60$ and 120 minutes following the oCRF infusion. Subjects were kept supine throughout the procedure, and had blood pressure and pulse monitored every 15 minutes. No subject reported any subjective experience from the infusion of OCRF; the experiment was teminated at $4: 30 \mathrm{p} \cdot \mathrm{m}$. This paradigm is summarized in the lower portion of Figure 1 .

Sample Preparation. Blood samples were obtained via the previously described intravenous cannulae. Samples for $\gamma_{3} \mathrm{MSH}$ determination were collected into chilled EDTA-containing vacutainers and were immediately centrifuged at $4^{\circ} \mathrm{C}$; the resulting plasma was acidified to $\mathrm{pH} 2$ with $1 \mathrm{~N} \mathrm{HCl}$, and immediately stored at $-70^{\circ} \mathrm{C}$. For extraction, the plasma samples were pooled as either pre- or post-oCRF infusion for each subject. The pooled plasma samples were then extracted with Sep-Pak $C_{18}$ cartridges as has been previously described for extracting B-endorphin from human plasma (7). We consistently achieve $85-90 \%$ recovery of $\gamma_{3} \mathrm{MSH}$ using this procedure. The extracts were then lyophilized and the dried material stored at $-70^{\circ} \mathrm{C}$ until further processing.

Blood samples for corticosteroid determination were collected into chilled heparin-containing vacutainers. These samples were immediately centrifuged at $4^{\circ} \mathrm{C}$, the plasma removed and stored at $-70^{\circ} \mathrm{C}$ until assayed.

Gel chromatrography. Extracted plasma samples prepared for $\gamma_{3} \mathrm{MSH}$ determination (equivalent to $80-100 \mathrm{ml}$ of plasma) were resuspended in $400 \mathrm{ul}$ $0.1 \%$ formic acid and applied to a Sephadex G-50 column $(0.9 \times 90 \mathrm{~cm})$. The column was developed in $0.1 \%$ formic acid, and $2 \mathrm{ml}$ fractions collected. Each fraction was dried by lyophilization, and resuspended in methanol/0.1 N HCl $(50 / 50)$ for $\gamma_{3}$ MSH quantitation by radioimmunoassay. Recovery of $\gamma_{3}$ MSH-IR from this column was $90 \%$.

Assays. $\gamma_{3} \mathrm{MSH}$ concentrations were determined by a specific radioimmunoassay that we have developed. The antibody is directed against a midportion region of $\gamma_{3} \mathrm{MSH}$ (His ${ }^{5}-\mathrm{Arg}^{\mathrm{I}}{ }^{4}$ ), and was raised in rabbits against synthetic bovine $\gamma_{3} \mathrm{MSH}$ conjugated to bovine serum albumin (34). The assay was performed in a $50 \mathrm{mM}$ phosphate buffer, $\mathrm{pH} 7.6$, containing $0.12 \mathrm{M} \mathrm{NaCl}, 0.004 \mathrm{M}$ EDTA, $0.016 \%$ $\mathrm{NaN}_{3}, 1.6 \%$ rabbit serum, and $0.1 \%$ polylysine. The standards (synthetic human Lys $\left.-\gamma_{3} \mathrm{MSH}\right)$ and samples were added in $50 \mathrm{ul}$ methanol/0.1 N HCl (50/50). The antiserum was added in $100 \mathrm{ul}$ of buffer, at a final dilution of $1: 25,000$. The radioligand was human $\left[{ }^{125} \mathrm{I}\right]-\mathrm{Lys}-\mathrm{Y}_{3} \mathrm{MSH}$, which was iodinated by the 
chloramine-T method [16]; 20,000 counts in 100 ul of buffer were added per tube. The assay was run in a final volume of 250 ul under disequilibrium conditions for $48-72 \mathrm{hrs}$ at $4^{\circ} \mathrm{C}$. Separation was by immunoprecipitation by addition of $15 \mathrm{ul}$ of sheep-anti-rabbit IgG per tube. This assay has a sensitivity of < 1 fmoles/tube, an $I_{20}$ of 2 fmoles/tube, and an $I_{50}$ of 32 fmoles/tube under disequilibrium conditions. Samples containing $\gamma_{3} M S H-I R$ in this study typically were read in the portion of the standard curve resulting in 20-30\% inhibition. The antiserum has less than $1 \%$ cross-reactivity with $\gamma_{1} \mathrm{MSH}$, Lys- $\gamma_{1} \mathrm{MSH}, \gamma_{2} \mathrm{MSH}, \mathrm{B}$-endorphin, ACTH, $\alpha-\mathrm{MSH}, \mathrm{B}-\mathrm{MSH}, \beta$-endorphin, and met-enkephalin. The intrassay coefficient of variation is $4.9 \%$, and the interassay coefficient of variation is $10.8 \%$.

Total plasma corticosteroids were quantitated by the competitive protein binding technique of Pegg and Keane (26) as modified by de la Pena and Goldzieher (11). The sensitivity of this assay is $0.3 \mathrm{ug} / \mathrm{d} 1$. The intra- and inter-assay coefficients of variation are $2.0 \%$ and $7.1 \%$, respectively.

Concanavalin A Affinity Chromatography. The pre- and post-oCRF infusion plasma samples from subjects 6 and 7 were subjected to gel filtration chromatography as described above, and those fractions corresponding to $4 \pm 1 \mathrm{~K}$ and $9+1 \mathrm{~K}$, as well as the fractions constituting the void volume of the column $(>13 \mathrm{~K})$ for each subject and for each condition (pre- and post-oCRF) were pooled. These samples were dried by lyophilization. To determine if the $r_{3}$ MSH IR in these peaks existed in a glycosylated form, each peak was subjected to Concanavalin A (Con A) - Sepharose 4B chromatography, as described by Shibasaki et al. (30). Briefly, samples were resuspended in 500 ul of buffer and applied to a 500 ul Con A column that had been equilibrated with buffer. Glycosylated peptides were eluted by increasing concentrations of $\alpha$-methy 1-D-mannopyranoside and finally $0.1 \mathrm{M}$ acetic acid. $1 \mathrm{ml}$ fractions from these columns were collected, dried, and assayed for $\gamma_{3}$ MSH by the previously described RIA.

Statistics. Comparisons between pre- and post-oCRF infusion levels of IR- $\gamma_{3} \mathrm{MSH}$ and cortisol were by paired t-tests. Results are means $\pm \mathrm{S} . \mathrm{E} . \mathrm{M}$. unless stated otherwise.

\section{RESULTS}

We desired to demonstrate that any effect we might find on plasma $\gamma_{3}$ MSH levels in this study was specific to the OCRF infusion, as opposed to any non-specific stress effects. The average response of plasma cortisol to oCRF is shown in figure 1. The mean baseline cortisol level remained unperturbed by the control injections, but showed a rapid increase within 10 minutes of the oCRF injection, returning to baseline levels after several hours. These data suggest that the OCRF is poysiologically active and able to reach the pituitary and facilitate the release of POMC-derived peptides (i.e., ACTH, as indirectly observed by the increase in plasma cortisol), and that the endocrine effect seen is specific to the oCRF injection, and not a stress response to injections per se (as indicated by unchanging baseline cortisol levels pre- and post-control injections).

The $Y_{3}$ MSH-IR from a typical subject is shown in Figure 2. Immunoreactivity both pre- and post-oCRF infusion was found in fractions of the void volume of the Sephadex G-50 column (molecular weight $>13 \mathrm{~K}$ ), in 
fractions of $8-10 \mathrm{~K}$ (fractions $\# 31-35$ ), and in a collection of smaller peaks of 3.1-5.0K (fractions \$41-55). In several subjects (including the one shown in Figure 2), several fractions with molecular weights less than $3.1 \mathrm{~K}$ contained $\mathrm{r}_{3} \mathrm{MSH}-\mathrm{IR}$. The immunoreactivity in these fractions presumably is due to smaller forms of $\gamma_{3} \mathrm{MSH}$, although not to the predicted cleavage products $\gamma_{2} \mathrm{MSH}$ or $\gamma_{1} \mathrm{MSH}$, as the antiserum does not recognize these specific peptides. The total plasma $Y_{3}$ MSH-IR before and after oCRF infusion for each subject is summarized in Figure 3. Each subject manifested an increased plasma leve1 of total $\gamma_{3}$ MSH-IR after injection of oCRF, ranging from a 1.3 to 16.5 fold elevation. The mean group change from pre- to post- infusion was from $0.26 \pm$ 0.09 fmoles $/ \mathrm{m} 1$ to $0.53 \pm 0.11$ fmoles $/ \mathrm{m} 1$, a 2.0 fold increase $(t=-3.146, p<$ $0.01)$. Similarly, the mean group plasma cortisol levels measured at the same two time points increased 2.4 fold, from $6.14 \pm 1.21 \mathrm{ug} / \mathrm{d} 1$ to $14.98 \pm 1.83$ $\mathrm{ug} / \mathrm{d} 1(\mathrm{t}=-8.393, \mathrm{p}<0.0005)$.

To determine which forms of $\gamma_{3}$ MSH-IR contributed to the observed 2-fold increase of total $\gamma_{3} M S H-I R$, the amount of immunoreactivity found in the 3-5K (" $4 \mathrm{~K}$ "), 8-10K (" $9 \mathrm{~K}$ "), and void volume ( $>13 \mathrm{~K}$ ) fractions both before and after
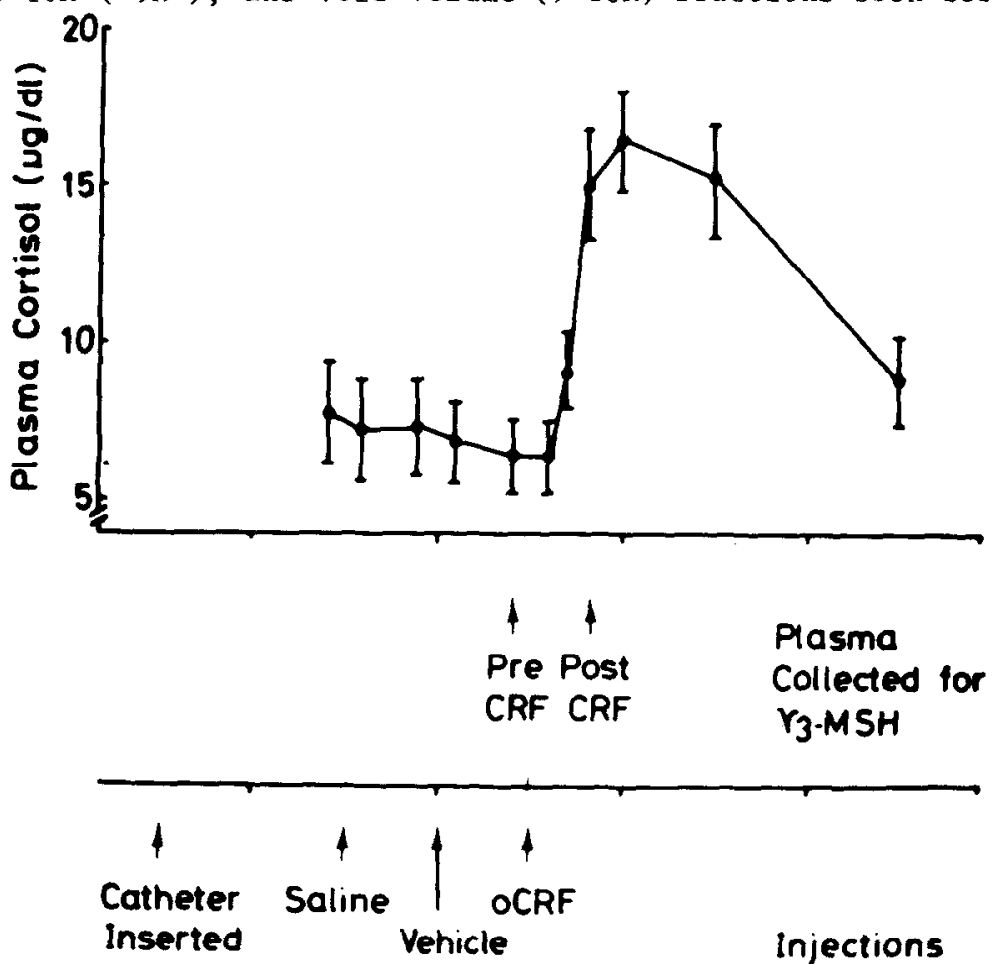

\section{3:00hrs $14: 00 \quad 15: 00 \quad 16: 00 \quad 17: 00$}

Time

Figure 1. Plasma cortiso1 levels in seven subjects at various times before and after control and oCRF injections. Data are means \pm S.E.M. The lower half of the figure summarizes the times of the injections and sample collections. 


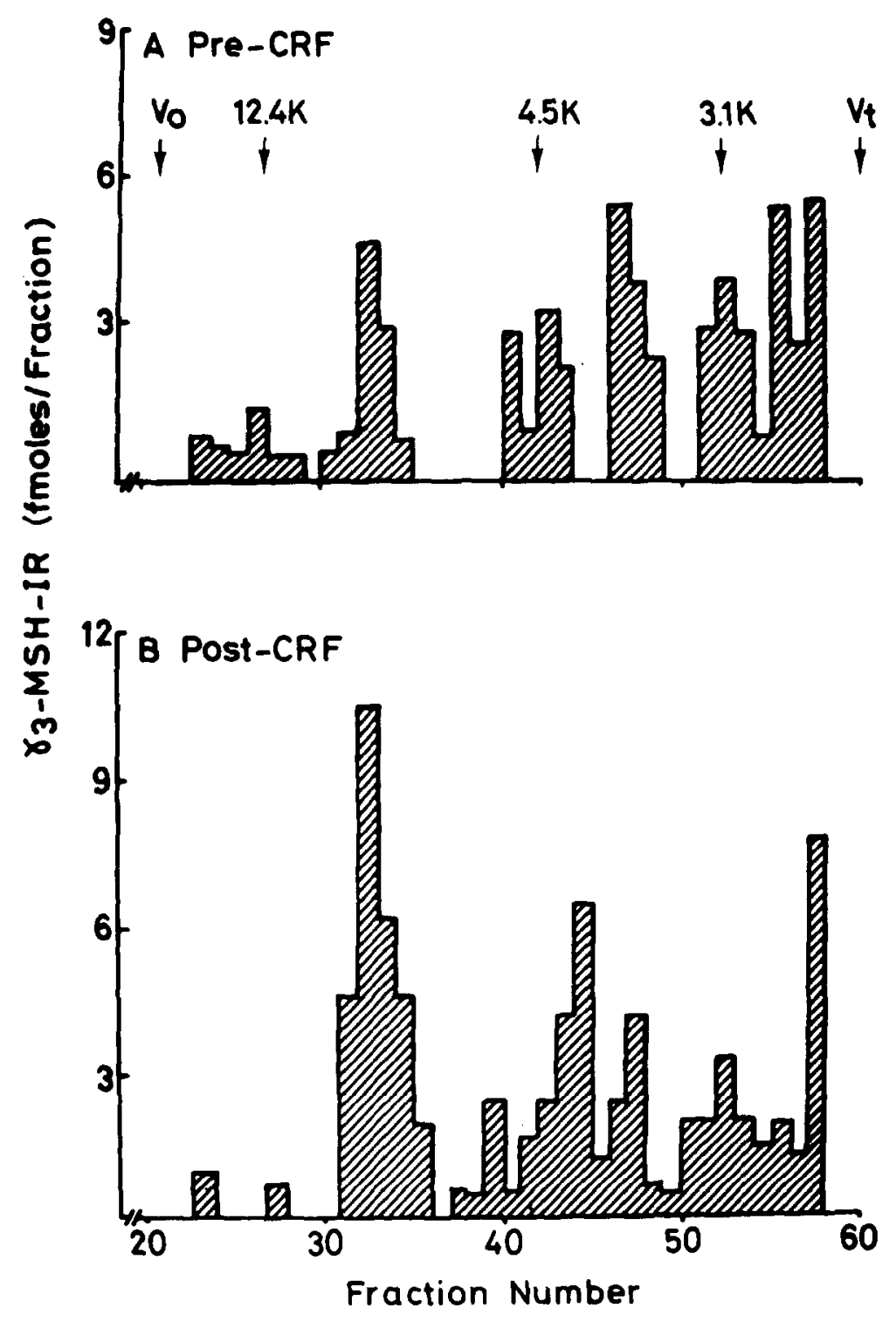

Figure 2. Representative Sephadex G-50 gel filtration profiles of $\gamma_{3}$ MSH-IR in extracted plasma samples both pre- and post-oCRF infusion (Subject 3). Molecular weights of peptide standards are indicated (12.4K, cytochrome C; $\left.4.5 \mathrm{~K},\left[\mathrm{I}^{125}\right]-\mathrm{ACTH} ; 3.1 \mathrm{~K},\left[\mathrm{I}^{125}\right]-\gamma_{3} \mathrm{MSH}\right)$. 
OCRF infusion was determined from the gel filtration elution profiles (Figure 2) for each subject. These data are shown in Figure 4. The total increase of $\gamma_{3}$ MSH-IR was attributable to elevations of both the $9 \mathrm{~K}$ fractions, which rose from a mean level of $0.79 \mathrm{fmoles} / \mathrm{ml}$ to 2.08 fmoles $/ \mathrm{ml}(t=-1.609, p<0.1)$, and the $4 \mathrm{~K}$ fractions, which increased from 0.10 to 0.19 fmoles $/ \mathrm{m} 1$ ( $t=-2.515$, $p<0.025)$. There was no increase observed for the immunoreactivity found in the void fractions.

Because $\gamma_{3} \mathrm{MSH}$ has been reported to exist in a glycosylated form in bovine anterior pituitary as determined by Con A affinity chromatography [30], we attempted to determine if human plasma $\gamma_{3} \mathrm{MSH}-\mathrm{IR}$ was glycosylated in two of these subjects. The $4 \mathrm{~K}, 9 \mathrm{~K}$ and void fractions, both pre- and post-oCRF infusion were found to be glycosylated. Between 80 and $100 \%$ of the $\gamma_{3} \mathrm{MSH}-\mathrm{IR}$ in the $4 \mathrm{~K}$ fractions was retained by Con A columns; $89-100 \%$ of the $9 \mathrm{~K}$ fractions and $69-100 \%$ of the void volume fractions were similarly retained. A representative experiment is summarized in Figure 5. In a control experiment, less than $10 \%$ of synthetic human $\gamma_{3} \mathrm{MSH}$ was retained by a Con A column.
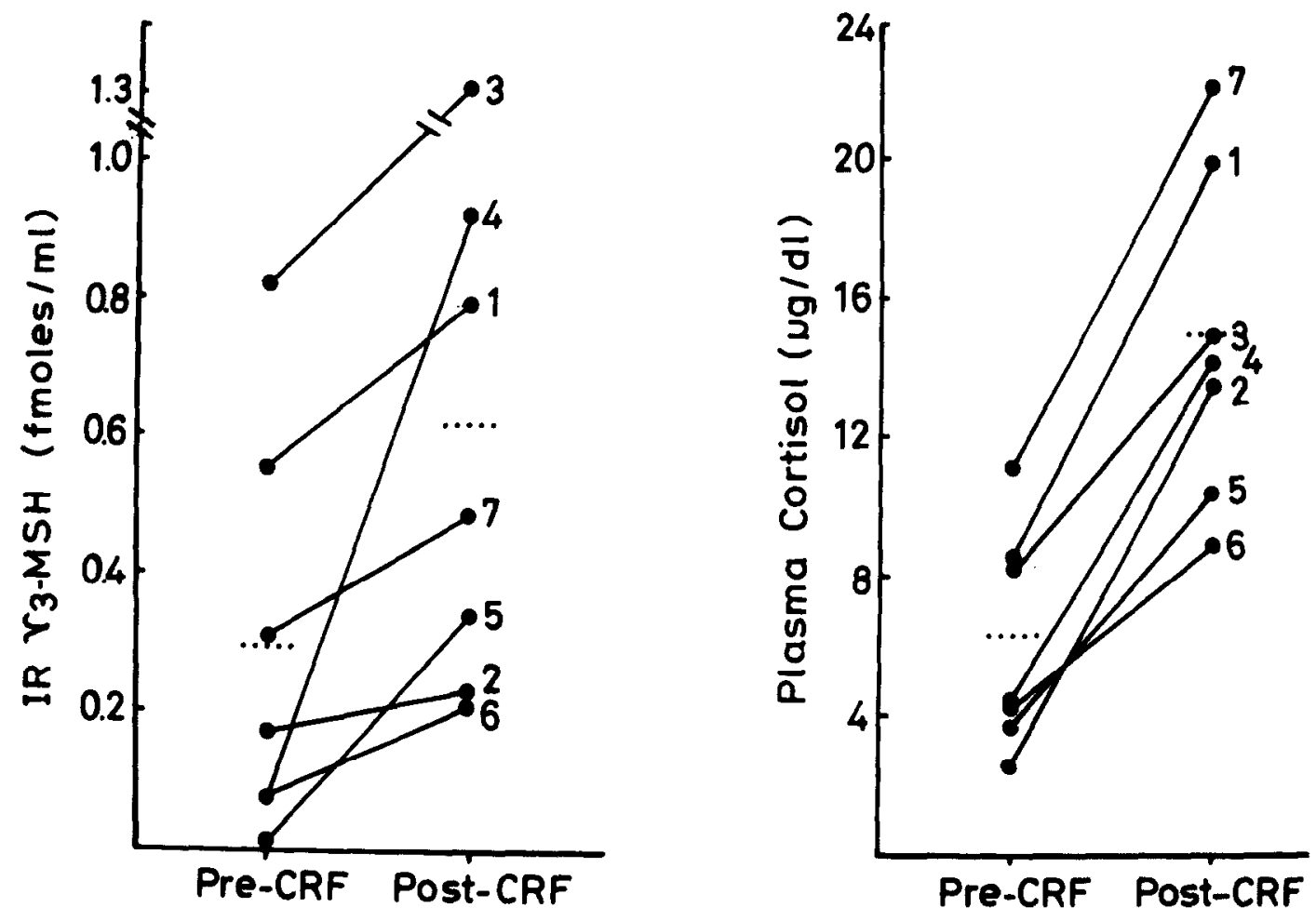

Figure 3. Plasma concentrations of total $\gamma_{3} \mathrm{MSH}-\mathrm{IR}$ and cortisol in seven subjects both pre- and 15 minutes post-oCRF infusion. The increase of mean plasma level (dotted lines) from pre- to post-oCRE infusion is significant for both $\gamma_{3} \mathrm{MSH}$ (paired t-test, $\mathrm{p}<0.01$ ) and cortisol (paired t-test, $\mathrm{p}<$ $0.0005)$. 


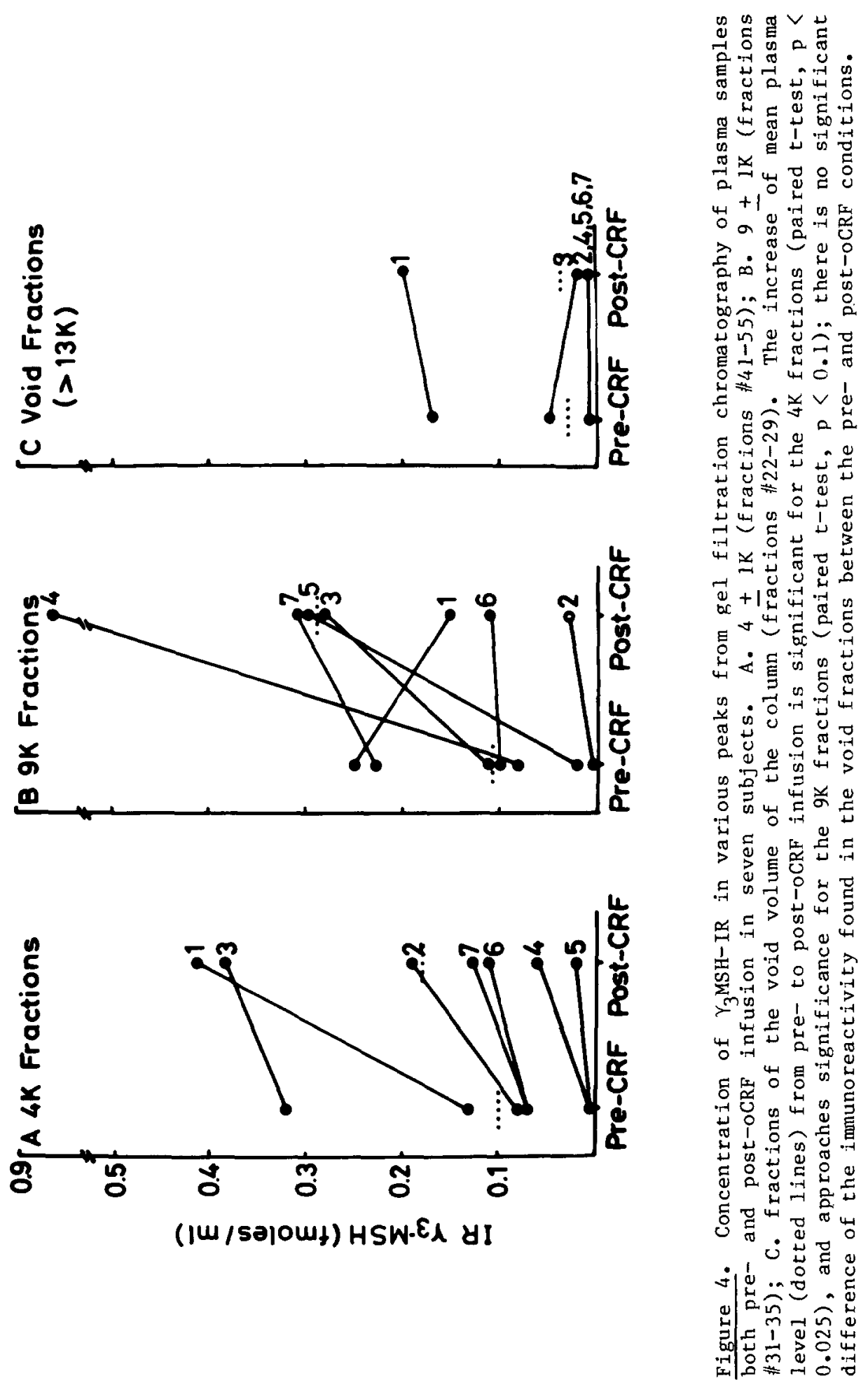




\section{DISCUSSION}

Ovine CRF infusion in the present study resulted in a doubling of total $\gamma_{3}$ MSH-IR in normal men, in reasonable agreement with several previous studies. Motomatsu and co-workers (20) found up to a two-fold increase in circulating levels of immunoreactive $N$-terminal peptide (POMC ${ }^{1-76}$ ) after injection of 100 ug of oCRF in 4 subjects. Hale and co-workers (14), using a radioimmunoassay specific for $\gamma_{3} \mathrm{MSH}$ demonstrated about a 1.5 -fold increase in $\gamma_{3} \mathrm{MSH}-\mathrm{IR}$ following injection of 100 ug of oCRF in 6 subjects. Using a much smaller dose of oCRF (5-7 ug), we were able to observe increases of the same order as previous investigators employing much higher oCRF doses. We selected the 0.1 $\mathrm{ug} / \mathrm{kg}$ dose of oCRF as we found in an earlier study (Watson, S.J., Lopez, J., Young, E.A., Vale, W., Rivier, J., Akil, H., submitted) that this results in plasma levels of $O C R F$ in the normal physiological range. It may be that the pool of releasable $\gamma_{3} \mathrm{MSH}$ is limited and that the system is maximally driven

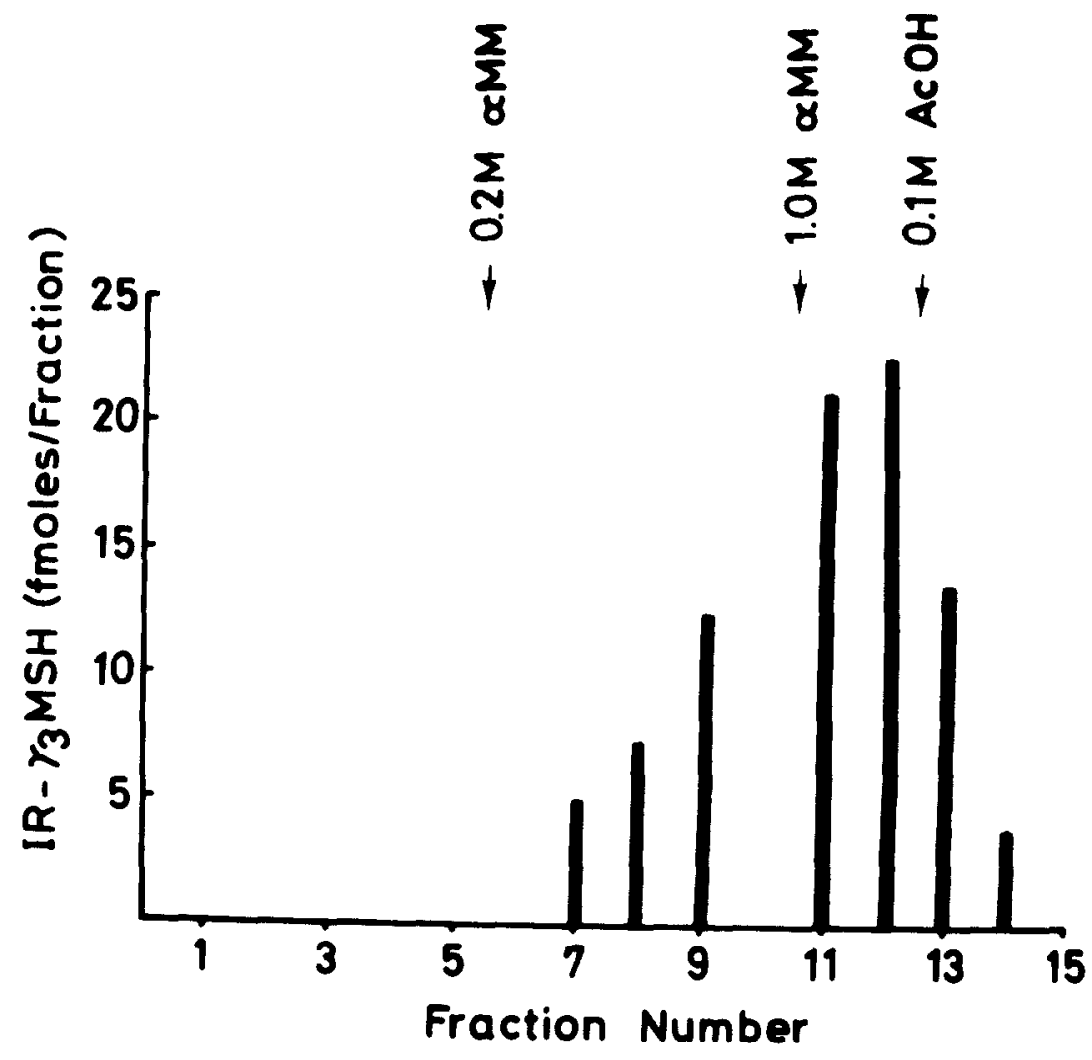

Figure 5. Representative elution profile of $\gamma_{3}$ MSH-IR in plasma from a Concanavalin A (Con A)-Sepharose 4B affinity column. Plasma samples were chromatographed on a Sephadex G-50 column as described in the text, and the $4 \mathrm{~K}, 9 \mathrm{~K}$, and void volume peaks pooled. Each peak was then chromatographed on a Con A-Sepharose 4B affinity column. Glycosylated material was eluted with increasing concentratons of $\alpha$-methyl-D-mannopyranoside $(\alpha M M)$ and $0.1 M$ acetic acid $(\mathrm{AcOH})$. This profile is for the $4 \mathrm{~K}$ fractions of subject 6 following oCRF infusion. 
after being exposed to this low-dose infusion of OCRF, so that the infusion of more oCRF, at least in the short run, is incapable of facilitating the release of more $\gamma_{3} \mathrm{MSH}$.

The forms of $\gamma_{3}$ MSH-IR released following oCRF stimulation in normal humans have not been elucidated $(14,20)$. Using an antibody directed against the N-terminal peptide of POMC (POMC ${ }^{1-76}$ ), Chan et al. (10) demonstrated the release of two forms of $\gamma$-MSH-IR, a B-lipotropin-sized $(10-11 \mathrm{~K})$ and a larger form, from cultured human anterior pituitary cells following oCRF stimulation. The major forms of $\gamma_{3}$ MSH-IR detected in the present investigation were $4 \mathrm{~K}$ and 9K forms, presumably representing native, glycosylated $\gamma_{3} \mathrm{MSH}$, and $\gamma_{3} \mathrm{MSH}$ extended with the extreme N-terminal fragment of $\operatorname{POMC}(4,10,14,19,28)$, although extension of $\gamma_{3} \mathrm{MSH}$ with joining peptide has been reported in porcine pituitary (6). One might argue that larger forms were present, but due to sample collection or processing methods, breakdown was allowed to occur and we measured these breakdown products instead of the native circulating forms. While this is a possibility it seems unlikely, as this same procedure preserves intact the multiple molecular species of ACTH and B-endorphin. Inspection of Figure 1 indicates several peaks in the $3-5 \mathrm{~K}$ range. The column system utilized for separation in this study is one we have previously developed for resolving different forms of B-endorphin; the observed peaks actually differ from each other only by a few hundred daltons. The reason for this heterogeneity is not apparent, but probably reflects variable degrees of glycosylation of intact $\gamma_{3} \mathrm{MSH}$, or some other form of post-translational modification.

While smaller forms of $\gamma_{3}$ MSH-IR exist in human plasma under normal physiological conditions, it may be that the processing of the N-terminal domain of POMC is altered in various pathological states. A number of investigators have determined the sizes of $\gamma_{3}$ MSH-IR under other conditions. Nakao et al. (22) demonstrated a large form (B-lipotropin-sized, 10-11K) in plasma from patients with Addison's and Nelson's syndromes. Another report (5) showed a $16 \mathrm{~K}$ form in Nelson's syndrome patients' plasma, and both a $16 \mathrm{~K}$ and a smaller form in tumor extract and plasma of a patient with ectopic ACTH syndrome. Tanaka et al. (33) showed an increase in $16 \mathrm{~K}$-sized $\gamma_{3} \mathrm{MSH}-\mathrm{IR}$ following metyrapone in normal males. In general, the observed forms of $\gamma_{3}$ MSH-IR in these non-physiological states tends to be large. of interest, however, is the report of Watsman et al. (35), which demonstrated elevations of $4 \mathrm{~K}, 6 \mathrm{~K}$ and $11 \mathrm{~K}$ forms of $\gamma_{3} \mathrm{MSH}-\mathrm{IR}$ following "maximal stress" (cardiac arrest). While cardiac arrest cannot be considered a "normal" stressor, it would cause maximal driving of physiological regulatory mechanisms; it is of note that these authors found smaller forms of $\gamma_{3}$ MSH-IR under these circumstances. The release of smaller forms of $\gamma_{3}$ MSH-IR following oCRF stimulation has not been previously reported; the results of the present study suggest that this physiological perturbation results in the release of processed forms of $\gamma_{3} \mathrm{MSH}$.

The release of smaller, processed forms of $\gamma_{3}$ MSH-IR under physiological conditions may be endocrinologically relevant. The smallest form of $Y_{3}$ MSH-IR $\left(\gamma_{3} \mathrm{MSH}, 3-4 \mathrm{~K}\right)$ has been shown to have the ability to bind to the adrenal cortex (25) and enhance ACTH-induced steroidogenesis $(1,2,13,24)$. No physiological action has been demonstrated for the larger forms of $\gamma_{3}$ MSH-IR. It is interesting to note that the vast majority of circulating $\gamma_{3} \mathrm{MSH}-\mathrm{IR}$ at both rest and post-CRF stimulation is of $4 \mathrm{~K}$ and $9 \mathrm{~K}$ sizes. On the other hand, there 
have been several communications $(12,27,29,31)$ indicating that human pituitary contains predominately a larger form (i.e., B-1ipotropin-sized) of $\gamma_{3} \mathrm{MSH}-\mathrm{IR}$, similar to reports of bovine pituitary $(3,32)$. Young et al. (37), however, have recently demonstrated in the rat that although B-lipotropin is the primary product stored in the anterior lobe, CRF promotes the preferential release of $B$-endorphin into plasma. Thus, the findings of the current study are not altogether surprising; it may be that in the human, the POMC products $B$-endorphin and $\gamma_{3}$ MSH are stored in the pituitary as larger peptides, but the smaller, possibly more biologically active forms may be preferentially released.

We also determined that the circulating forms of $\gamma_{3}$ MSH-IR in human plasma are to a large extent glycosylated. The determination of glycosylation of $\gamma_{3}$ MSH has not been previously reported in human plasma, but is in agreement with the finding of glycosylated forms of $\gamma_{3}$ MSH-IR in bovine anterior and intermediate pituitary (30) and in human pituitary (4). The significance of this post-translational modification is not known, but may facilitate the biochemical activity of this peptide, or may protect it from intracellular degradation ( 30$)$.

The function of $\gamma_{3} \mathrm{MSH}$ is not known. That circulating levels of processed, possibly physiologically active forms of this peptide are significantly elevated following oCRF infusion suggests that $Y_{3}$ MSH serves a role in modulating the neuroendocrine responses of the hypothalamic-pituitary-adrenal axis.

\section{ACRNOWLEDGMENTS}

The secretarial assistance of Carrie Sercel and Adele Henry is greatly acknowledged. This'work was supported in part by NIMH Grant \#MH 36168 (to S.J.W. and H.A.), and by the Department of Psychiatry, University of Michigan.

\section{REFERENCES}

1. A1-Duifaili, E.A.S., Hope, J., Estivariz, F.E., Lowry, P.J. and Edwards,

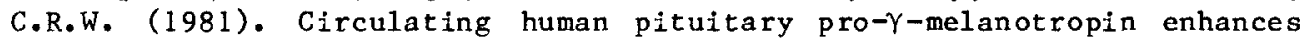
the adrenal response to ACTH. Nature 291: 156-158.

2. Al-Duijaili, E.A.S., Williams, B.C., Edwards, C.R.W., Salacinski, P. and Lowry, P.J. (1982). Human $\gamma$-melanotropin precursor potentiates corticotropin-induced adrenal steroidogenesis by stimulating mRNA synthesis. Biochem. J. 204: 301-305.

3. Benjannet, S., Seidah, N.G., Routhier, R. and Chretien, M. (1980). A novel human pituitary peptide containing the $\gamma$-MSH sequence. Nature 285: 415-416.

4. Bennett, H.P.J., Seidah, N.G., Benjannet, S., Solomon, S. and Chretien, M. (1986). Reinvestigation of the disulfide bridge arrangement in human pro-opiomelanocortin N-terminal segment (hNT 1-76). Int. J. Peptide Protein Res. 27: 306-313. 
- Bertagna, X., Seurin, D., Pique, L., Luton, J.P., Bricaire, H: and Girard, F. (1983). Peptides related to the $\mathrm{NH}_{2}$-terminal end of proopiocortin in man. J. Clin. Endocrinol. Metab. 56:489-495.

- Boileau, G., Lariviere, N., Hsi, K.-L., Seidah, N.G. and Chretien, M. (1982). Characterization of multiple forms of porcine anterior pitutary proopiomelanocortin amino-terminal glycopeptide. Biochemistry 21: 5341-5346.

- Cahill, C.A., Matthews, J.D. and Akil, H. (1983). Human plasma B-endorphin-like peptides: A rapid, high recovery extraction technique and validation of radioimunoassay. J. Clin. Endocrinol. Metab. 56: 992-997.

- Callahan, M.F., Kirby, R.F., Lymang rover, J.R., Johnson, A.K. and Gruber, K.A. (1984). Cardiovascular mechanisms of gamma $(\gamma)_{2}-\mathrm{MSH}$. Clin. Exp. Hypertens. A6: 1727-1730.

- Callahan, M.F., Kirby, R.F., Wolff, D.W., Strandhoy, J.W., Lymangrover, J.R., Johnson, A.K. and Gruber, K.A. (1985). Sympathetic nervous system mediation of acute cardiovascular actions of $\gamma_{2}$-melanocyte stimulating hormone. Hypertension 7: I-145-I-150.

- Chan, J.S.D., Lu, C.-L., Seidah, N.G. and Chretien, M. (1982). Corticotropin Releasing Factor (CRF): Effects on the release of pro-opiomelanocortin (POMC)-related peptides by human anterior pituitary cells in vitro. Endocrinology 111: 1388-1390.

- de la Pena, A. and Goldzieher, J.W. (1977). Practical determination of total plasma cortisol by use of competitive protein binding. In: Cooper, G.R. and King, I.S. (eds.) Selected Methods of Clinical Chemistry. American Association for Clinical Chemistry, Washington, D.C.

. Estivariz, F.E., Hope, J., McLean, C. and Lowry, P.J. (1980). Purification and characterization of a $\gamma$-melanotropin precursor from frozen human pituitary glands. Biochem. J. 191: 125-132.

3. Farese, R.V., Ling, N.C., Sabir, M.A., Carson, R.E. and Trudeau, W.L. III. (1983). Comparison of effects of adrenocorticotropin and lys- $\gamma_{3}$-melanocyte-stimulating hormone on steroidogenesis, adenosine 3', 5'-monophosphate production, and phospholipid metabolism in rat adrenal fasciculata-resticularis cells in vitro. Endocrinology 112: 129-132.

4. Hale, A.C., Ratter, S.J., Tomlin, S.J., Lytras, N., Besser, G.M. and Rees, L.H. (1984). Measurement of immunoreactive $\gamma-M S H$ in human plasma. Clin. Endocrino1. 21: 139-148.

5. Hope, J., Ratter, S.J., Estivariz, F.E., McLoughin, L. and Lowry, P.J. (1981). Development of a radioimmunoassay for an amino-terminal peptide of pro-opiocortin containing the $\gamma$-MSH reglon: Measurement and characterization in human plasma. C1in. Fndocrinol. 15: 221-227. 
16. Hunter, W.M. and Greenwood, F.C. (1962). Preparation of 131 I-labelled human growth hormone of high specific activity. Nature 194: 495-496.

17. Klein, M.C., Hutchins, P.M., Lymangrover, J.R. and Gruber, K.A. (1985). Pressor and cardioaccelerator effects of gamma MSH and related peptides. Life Sci. 36: 769-775.

18. Ling, N., Ying, S., Minick, S. and Guillemin, R. (1979). Synthesis and biological activity of $\gamma$-melanotropin peptides derived from the cryptic region of the adrenocorticotropin/B-1ipotropin precursor. Life Sci. 25: 1773-1780.

19. Lymang rover, J.R., Buckalew, V.M., Harris, J., Klein, M.C. and Gruber, K.A. (1985). Gamma-2 MSH is natriuretic in the rat. Endocrinology 116: 1227-1229.

20. Motomatsu, T., Takahashi, H., Ibayashi, H. and Nobunaga, M. (1984). Human plasma proopiomelanocortin $\mathrm{N}$-terminal peptide and adrenocorticotropin: Circadian rhythm, dexamethasone suppression, and corticotropin-releasing hormone stimulation. J. Clin. Endocrinol. Metab. 59: 495-498.

21. Nakanishi, S., Inoue, A., Kita, T., Nakamura, M., Chang, A.C.Y., Cohen, S.N. and Numa, S. (1979). Nucleotide sequence of cloned cDNA for bovine corticotropin-B-lipotropin precursor. Nature 278: 423-427.

22. Nakao, K., Oki, S., Tanaka, I., Nakai, Y. and Imura, H. (1980). Concomitant secretion of $\gamma-\mathrm{MSH}$ with $\mathrm{ACTH}$ and $\mathrm{B}$-endorphin in humans. $\mathrm{J}$. Clin. Endocrino1. Metab. 51: 1205-1207.

23. Oka, M., Nagai, Y., Okamoto, K., Yasumura, K., Shimamura, S. and Yajima, H. $(1980)$. Effect of $\gamma$-melanotropin $(\gamma-\mathrm{MSH})$ on the conditioned behavior. J. Pharm. Dyn. 3: 628-630.

24. Pedersen, R.C., Brownie, A.C. and Ling, N. (1980). Pro-adrenocorticotropin/endorphin-derived peptides: Coordinate action on adrenal steroidogenesis. Science 208: 1044-1046.

25. Pedersen, R.C. and Brownie, A.C. (1983). Lys- $\gamma_{3}$-melanotropin binds with high affinity to the rat adrenal cortex. Endocrinology 112: 1279-1287.

26. Pegg, P.J. and Keane, P.M. (1969). The simultaneous estimation of plasma cortisol and transcortin binding characteristics by a competitive protein binding technique. Steroids 14: 705-715.

27. Seidah, N.G. and Chretien, M. (1981). Complete amino acid sequence of a human pituitary glycopeptide: An important maturation product of proopiomelanocortin. Proc. Nat1. Acad. Sci. USA 78: 4236-4240.

28. Seidah, N.G., Rochemant, J., Hamelin, J., Benjannet, S. and Chretien, M. (1981). The missing fragment of the pro-sequence of human proopiomelanocortin: Sequence and evidence for C-terminal amidation. Biochem. Biophys. Res. Commun. 102: 710-716. 
29. Seidah, N.G., Rochemant, J., Hamelin, J., Lis, M. and Chretien, M. (1981). Primary structure of the major human pituitary proopiomelanocortin $\mathrm{NH}_{2}$-terminal glycopeptide. J. Biol. Chem. 256: 7977-7984.

30. Shibasaki, T., Ling, N. and Guillemin, R. (1980). Pituitary immunoreactive $\gamma$-melanotropins are glycosylated oligopeptides. Nature 285: 416-417.

31. Tanaka, I., Nakai, Y., Jingami, H., Fukata, J., Nakao, K., Oki, S., Nakanishi, S., Numa, S. and Imura, H. (1980). Existence of $\gamma$-melanotropin $(Y-M S H)-1 i k e$ immunoreactivity in bovine and human pituitary glands. Biochem. Biophys. Res. Comun. 94: 211-217.

32. Tanaka, I., Nakai, Y., Nakao, K., Oki, S., Yoshimasa, T., Imura, H. (1983). $\gamma_{1}$-Melanotropin-like immunoreactivity in bovine and human adrenocorticotropin-producing tissues. J. Clin. Endocrinol. Metab. 56: 1080-1083.

33. Tanaka, I., Nakai, Y., Nakao, K., Yoshimasa, T., Oki, S. and Imura, H. (1984). Big form of $\gamma$-melanotropin-like immunoreactivity in normal human plasma. Peptides 5: 913-916.

34. Vaudry, H., Jenks, B.G., van Overbeeke, A.P. (1984). Biosynthesis, processing and release of pro-opiomelanocortin related peptides in the intermediate lobe of the pituitary gland of the frog (rana ridibunda). Peptides 5: 905-912.

35. Wortsman, J., Frank, S., Wehrenberg, W.B., Petra, P.H. and Murphy, J.E. (1985). $\gamma_{3}$-melanocyte-stimulating hormone immunoreactivity is a component of the neuroendocrine response to maximal stress (cardiac arrest). J. Clin. Endocrinol. Metab. 61: 355-360.

36. Young, E.A. and Akil, H. (1985). CRF stimulation of ACTH/B-endorphin release: Effects of acute and chronic stress. Endocrinology 117: 23-30.

37. Young; E.A., Lewis, J. and Akil, H. (1986). The preferential release of beta-endorphin from the anterior pituitary lobe by CRF, Peptides 7: 603-607.

Received 25 February 1987

Accepted 11 March 1987 